\title{
Impacts of the Migration of Cross-Cutting Courses of a Traditional University in Distance Learning
}

\author{
https://doi.org/10.3991/ijep.v9i2.9945 \\ Mouhamadou Lamine Ba ${ }^{\square}$ ), Bounama Gueye, Amadou Dahirou Gueye, Omar Kassé \\ Université Alioune Diop de Bambey, Bambey, Senegal \\ mouhamadoulamine.ba@uadb.edu.sn \\ Marie Héléne Wassa Mballo \\ Agence Universitaire de la Francophonie, Dakar, Sénégal
}

\begin{abstract}
Public universities in Senegal are facing huge issues related to the reception and training of students. Given the budget deficit in Senegal and in African countries in general, our leaders struggle to continuously invest in the human and material resources within the universities. In addition, the courses taught in traditional programs are most often repetitive and sometimes not up-to-date, which does not allow universities to optimize time, space, human resources, and finance. As a result, it became acute to adapt the learning models and teaching methods within the traditional universities. Distance learning seems to be an essential solution. However, existing distance learning offers in these universities are in general geared towards certifying and degree-based distance learning. This does not solve the problems encountered in classical pedagogical training. Starting from these limits, we first propose a new efficient model of distance education at the service of a classical university, then we demonstrate its positive financial, material and pedagogical impacts. The proposed model has been implemented and successfully evaluated at Alioune Diop University of Bambey, a classical university in Senegal.
\end{abstract}

Keywords-Distance learning, Classical university, Cross-cutting courses, Pooling, Model, Optimization, Migration, Evaluation, Positive impacts.

\section{Introduction}

To fill the gap with rich states, emerging countries such as Senegal rely heavily on the education of their youth. As a result, a considerable effort has been made in this direction over the recent years, as evidenced by the increasing growth of the enrolment rate in elementary education in Senegal, which stood at between 80 and $93 \%$ in 2016 [1]. Such a trend is also observed in higher education. The number of baccalaureate holders continues to grow from year to year. This growth raises the problem of reception structures in higher education, as well as sufficient human and financial resources. Indeed, the state of Senegal, despite a clear desire to increase its power in terms of universities and the recruitment of higher education teachers through a new 
policy of higher education reform [2], is facing the harsh reality of the lack of financial resources inherent to an underdeveloped country.

This raises the question of how to optimize the material and human resources (classrooms, practical work materials, teaching staff, etc.) of Senegal's public universities, without decreasing the quality of the education provided. The use of digital technologies in education can undoubtedly help to solve the problem of massification of enrolments, but also and above all the problem of optimizing material, human, and financial resources in higher education institutions. Some distance learning models based on digital tools have already been tested in Senegal; see Section 2.2 for more details. However, many of these models offer a fully - fledged education system and therefore are not tailored for solving the difficulties that a traditional university may face. Our main contributions to this problem of optimizing resources of a classical university given cross-cutting courses under a limited budget are:

- The proposal in [3] of an efficient model of integration of distance learning in a traditional university. The main ideas underlying such a model are first the pooling (i.e. mutualisation) of cross-cutting courses, i.e. courses trained in classes of the same level but of different specialities, and then the migration of these pooled courses in distance learning;

- In this paper, the evaluation of the performances of our model and a demonstration of its positive pedagogical, material, and financial impacts in the results of the management of a classical university.

The remaining of this paper is structured as follows: In Section 2, we review the state - of - the - art of the integration of ICT in education at a global level and in Senegal particularly. In the same section, we also bring out the main challenges to be solve for a better integration of ICT in Senegalese education system. Then we summarize in Section 3 our distance-learning based model for pooling and migrating crosscutting courses of a traditional university in distance education; a more detailed description of the model is available in [3]. This proposed model will enable a classical university to optimize its material, pedagogical, and financial resources, thanks to the opportunities offered by distance learning. Finally, we prove the efficiency of our model by presenting in Section 4 its positive impacts in the practical scenario of its implementation and evaluation at Alioune Diop University of Bambey, a classical university in Senegal.

\section{Review of the State-of-the-Art}

In this section, we present a review of the state-of-the-art about the integration of ICTs in education at the global level and in Senegal particularly. We also point out some among the main challenges to tackle for a better integration of ICT in the Senegalese education system. We start by the literature at the global level. 


\subsection{Integration of ICT in education at the global level}

The importance of information technology integration in education is well established. Indeed, a number of studies $[4,5,6]$ have demonstrated the positive contribution of ICT to learner behavior. In other words, the successful integration of ICT into teaching increases the performance and success rate of learners with a real motivation that is noted. The authors of the book "Integration of ICT in Higher Education" [7, 8] identify several advantages that could result from a good integration of ICT in university pedagogy, namely:

- A better quality and greater efficiency in teaching;

- A higher graduation rate than in previous years;

- An easier access to information resources;

- An increased presence on global training markets.

The advent of the Internet [9] has greatly revolutionized the integration of ICT into teaching, which ensures real - time learning regardless of the geographical location of learners. Indeed, we are currently witnessing, on the one hand, totally online and distance education [10], and, on the other hand, hybrid forms of teaching methods or models $[11,32]$. This leads us to talk about the concept of ICT-assisted e-learning. This area is of great interest to researchers working on computer environments for learning. The main concern of ICT-assisted e-learning actors is how to successfully integrate ICT into teaching.

Thus, this community around computer environments for learning accompany and support universities, institutes and companies that wish to offer distance and online training. In this paper, we focus on the integration of ICT in higher education. Thus, universities that only provide online training are called virtual universities. They are found all over the world, for example the Virtual University of Senegal [12], the Canadian Virtual University [13], the TELUQ in Quebec [14], the Western Governors University [15] of the United States, the Open University [16] in England, the Virtual University [17] of the Université Libre de Bruxelles (ULB) in Belgium, etc. In Asia we are also witnessing the establishment of virtual universities such as the Open University Institute of Hanoi (IUOH) in Vietnam [18]. In sum, the success of ICT in the university system depends on a good planning strategy, which in turn depends on the following elements $[4,19,31,33]$ : the deployment of physical and technological infrastructures, didactic and pedagogical resources and teachers' skills.

This integration of ICT has enabled higher education institutions to embark on the digital path, which provides concrete solutions to the current international problems that higher education is facing. Among these issues, we can note the accessibility to training, adaptability and enrichment of teaching methods. Furthermore, universities are also integrating distance education to find ways of strengthening their role and place in the democratization of access to higher education. 


\subsection{Integration of ICT in Senegalese education}

Senegal is one of the countries in sub-Saharan Africa that are taking initiatives to promote the development and use of new technologies for and in education. Such momentum is supported from the outset by major partners such as Microsoft through the "Itl research" program [20] for innovations in teaching and learning through ICTs. Senegal was the sole African country selected in this Itl Research program when it was launched.

According to the ranking of the International Telecommunication Union (ITU), which measures the ICT Development Index (IDI) of a given country around the world, Senegal is pursuing significant development, first among WAEMU countries. Senegal was ranked 2nd behind Côte d'Ivoire, with an IDI of 2.66 [22] in 2017. Moreover, the project to interconnect universities [22], currently being finalized between the National Telecommunications Company [23], the State Computer Agency [24] and the Ministry of Higher Education, Research and Innovation of Senegal [25], demonstrates its willingness to effectively support ICTE. Hence the importance of promoting Education and Research Networks for access to digital training content and for research. In addition, many distance education projects in Senegal are supported by partners such as the Support Project for Higher Education Organization [26] and the Support Project for the Development of Information and Communication for Education Organization [27] as well as other partners such as the Francophone University Association (known as the "Agence Universitaire de la Francophonie" in French) [28].

Senegal is currently at the forefront of the use of information and communication technologies materialized by results, findings, and actions at the level of connectivity and ICT strategy, network infrastructure and equipment. The ICTE actions are carried on the one hand by the Virtual University of Senegal [12] and on the other hand by the Distance Training Institutes created in the classical higher education institutions. However, these institutions that are active in distance education are confronted with the challenges of learners' isolation and dropping out, although some authors are trying to find solutions by improving the functionalities of training platforms [29, 30]. Moreover, distance education practices in these institutions are heterogeneous and depend on the policies in need of distance education. Therefore, we consider that the integration of ICT in higher education in Senegal, seen here from the point of view of the supply of ODL in southern universities and higher education institutions, is confronted less with the availability of technological equipment and infrastructure than with social, human and purely organizational factors.

An effective solution to these challenges will probably have to take into account the current hypermedia dimension in the process of integrating ICT in education [22]. In this context, hyper media refers to the disproportionate resources allocated to equipments at the expense of the training of trainers and users. The model of integration of distance education in a traditional university that we propose in this work, reserves a significant part to the training of trainers and learners to the digital tools. 


\section{Distance Learning Model for Transversal Courses}

We have developed and presented in [3] a new model of distance learning that is tailored to conventional education. The originality and innovative character of this model comes from the pedagogical approach used, the targeted teachings, the technological support, and the practical application framework. Indeed, the model defines an educational approach of mutualisation of so-called transversal courses:

- Mutualisation phase deals with identifying cross-cutting courses and in getting teachers to agree on a single course at the same level;

- These courses are scripted and transposed online and remotely with a learner monitoring system based on synchronous and asynchronous tutorials provided by teachers from the field.

In the following we summarize the different building blocks of our model for integrating distance education in the pedagogy of a traditional university; for more details we defer the reader to [3].

\subsection{Process for identifying cross-cutting courses}

The first phase of our model of migration of the so-called transversal courses in online consists of the identification of the transversal constituent elements (CE) of the different teaching units of a classical university. Such a process of identifying transversal CE, summarized with the sequence diagram in Figure 1, is carried out using a 3 -step methodology, based on the models and syllabi of the different formations, as follows.

- Identification of candidate CE: crossing of training models of the same level, but of different specialities.

- Selection of so-called transversal CE: exploitation of the syllabi of the candidate $\mathrm{CE}$, and those with the same content are considered crosscutting.

- Final validation by teachers from the domain: the list of components resulting from the previous step is presented to a panel of teachers in the field. In this list, each $\mathrm{CE}$ is then examined by the experts for final validation.

This three-stage methodology has been implemented and evaluated in the training courses of the Alioune Diop University of Bambey in Senegal. The result of the candidate $\mathrm{CE}$ identification phase, by crossing the training models, is given by the table in Figure 2 for the "Expression and Communication Techniques" CE for Licence studies at the levels 1,2 and 3.

\subsection{Process of mutualisation and implementation of cross-cutting courses}

The second stage of our model, of a pure pedagogical nature, is the pooling of cross-cutting courses based on the use of the expertise of teachers in the targeted field. 


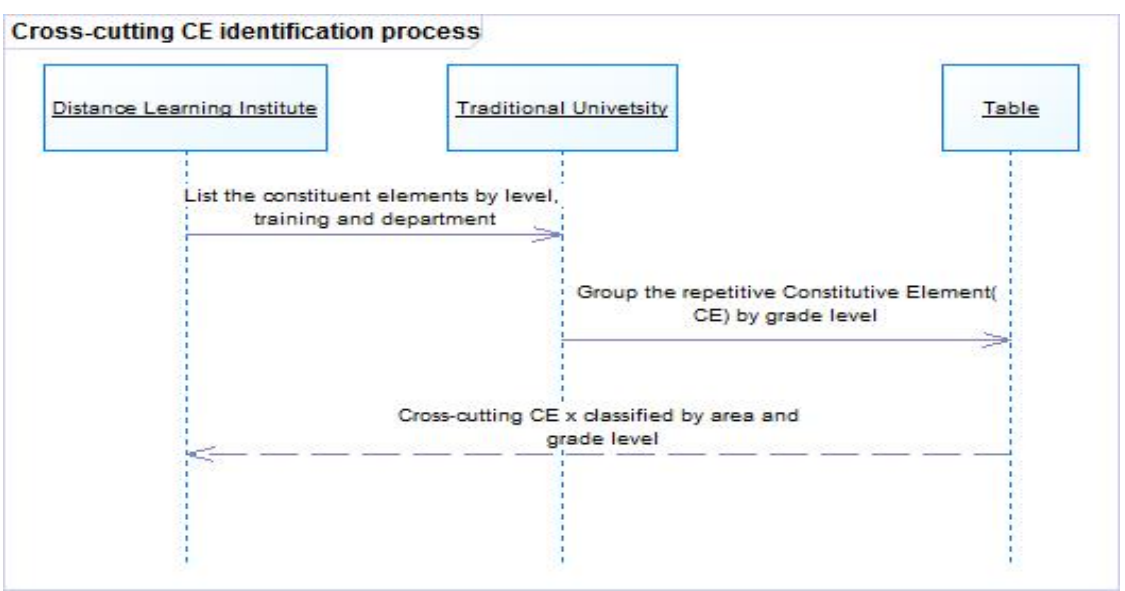

Fig. 1. Cross-cutting CE identification process

\begin{tabular}{|l|l|l|l|l|}
\hline Faculty & Department & Level & Course Code & course Name \\
\hline ECOMIJ & ECONOMIE & L3 & EA3542 & EA3542:Technique d'expression et de communication \\
\hline ECOMIJ & ECONOMIE & M1 & CCA5441 & CCA5441: Communication Professionnelle \\
\hline ECOMIJ & ECONOMIE & M1 & FEIF5441 & FEIF5441: Communication Professionnelle \\
\hline ECOMIJ & ECONOMIE & M1 & EA4141 & Technique d'expression et de communication \\
\hline ECOMII & ECONOMIE & M1 & EA4241 & Techniques d'expression et de communication \\
\hline ECOMIJ & MANAGEMENT & M1 & IDT5241 & Technique de modération, de communication participative \\
\hline ECOMII & MANAGEMENT & M1 & IAPP5242 & Techniques administratives \\
\hline SATIC & CHIMIE & L3 & CA3542 & CA3542: Techniques d'expression \\
\hline SATIC & MATH & L3 & SID3543 & SID3543: Technique d'expression \\
\hline SATIC & TIC & L2 & ART2341 & ART2341: Technique de communication \\
\hline SATIC & TIC & L3 & ART3611 & ART3611: Méthodologie \\
\hline SATIC & TIC & L3 & LPM3551 & LPM3551: Techniques d'expression \\
\hline SATIC & TIC & L3 & WEB2331 & WEB2331:Technique de communication \\
\hline SATIC & TIC & L3 & WEB3621 & WEB3621:Méthodologie \\
\hline SATIC & TIC & M1 & MC4242 & MIC4242: Techniques d'expression et de rédaction \\
\hline SATIC & TIC & M1 & MSI4242 & MSI4242:Techniques d'expression et de rédaction \\
\hline SDD & SC & L3 & SACOM3511 & SACOM3511: Techniques et Stratégies de Communication \\
\hline SDD & SC & L3 & SACOM5331 & SACOM5331: Communication \\
\hline SDD & SC & M1 & SACOM/NUT5331 & SACOMNUT5331: Communication \\
\hline & &
\end{tabular}

Fig. 2. Classification of the cross-cutting components by level, department and faculty for the course about the Expression and Communication Techniques

In the concrete case of Alioune Diop University of Bambey, the ECT course was the target and teachers of the given subject were asked to work on mutualisation. The sequence diagram in Figure 3 details the different stages of this mutualisation process; the work is carried out by a group of specialist teachers, under the supervision of a coordinator, who proposes a common content at the end. Once the pooling is done, we moved on to the stage of putting the course online; the results of setting up a pooled cross-cutting course in online within our platform [34] are illustrated in [3]. The shared course is first scripted by the techno-pedagogical team of the Open Training Institute (IFoAD) of Bambey according to the pedagogical objectives. The course is also produced in audio-visual format for the interactive aspects. For online and distance learning, we have opted for the MOODLE learning management system [31], which is the world leader in open distance and online learning platforms. 
Once the course is online, tutors and learners are trained in the use of the distance learning platform and tutoring. At the start of the lessons, the stages of learner followup and tutorials are launched. These two steps are the last two ones in our model, and their impacts in the pedagogical aspect of the management of the university are evaluated in Section 4.

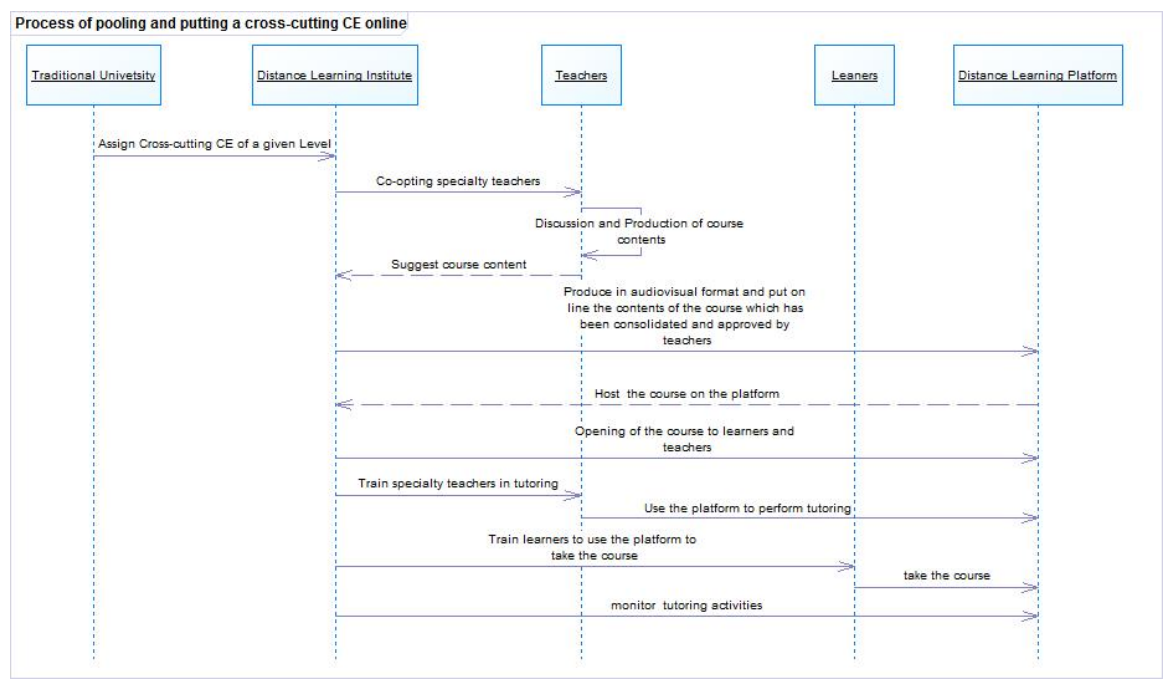

Fig. 3. Process for pooling and putting a cross-cutting component online

\section{$4 \quad$ Pedagogical and Financial Impacts of our Model}

This section presents the pedagogical and financial impacts inherent of the implementation of our proposed model at the Alioune Diop University of Bambey in Senegal. Such an evaluation of the contributions of our model has been done on the basis of the pooled cross-cutting ECT course taught on classes of the sames levels but of different specialities. We start the evaluation by detailing the results at the pedagogical point of view.

\subsection{Pedagogical impact}

The efficiency of our model of migration of the cross-cutting teachings in a classical university in distance learning has been studied from several angles: the suitability of our online learning offer, the quality of the presented online courses and other materials, the efficiency of our technical support, and the quality of the tutoring sessions. To evaluate those aspects, we conducted a survey over thirty two randomly chosen students from differents classes and levels

We asked them to reply to seven qualitative questions, which were rated on a fourelement Goodness-Scale. Table 1 summarizes the total number of students positively replying for every element of goodness. Besides the questions about the technical 
support and the interactions with the tutors, the students are mostly satisfied by the pedagogical aspects underlying our learning model.

Table 1. Answers of the questions about the quality of our online learning model for crosscutting courses in a classical university

\begin{tabular}{|c|c|c|c|c|}
\hline & $\begin{array}{l}\text { Rather } \\
\text { Good }\end{array}$ & Good & $\begin{array}{l}\text { Very } \\
\text { Good }\end{array}$ & Bad \\
\hline Are you satisfied by the online learning offer? & 18 & 3 & 2 & 9 \\
\hline Are you satisfied by the presentation of the online course? & 11 & 13 & 2 & 6 \\
\hline $\begin{array}{l}\text { Are you satisfied with our understanding and control of the con- } \\
\text { tent? }\end{array}$ & 13 & 9 & 1 & 9 \\
\hline What do you think about our technical support? & 10 & 6 & 1 & 15 \\
\hline $\begin{array}{l}\text { What do you think about the accessibility of the online platform } \\
\text { and courses? }\end{array}$ & 11 & 9 & 7 & 5 \\
\hline $\begin{array}{l}\text { What do you think about the self-evaluation tests included in the } \\
\text { online courses? }\end{array}$ & 6 & 12 & 8 & 6 \\
\hline $\begin{array}{l}\text { Are you satisfied regarding your various interactions with your } \\
\text { tutor? }\end{array}$ & 6 & 3 & 0 & 23 \\
\hline
\end{tabular}

Overall, we observe that the proposed model introduces flexibility into a conventional training, while guaranteeing a very high success rate compared to the face-toface version.

Optimization of the material and pedagogical resources: The first strong impact of the adoption of our model in a classical university is a better rationalization of the human and material resources. Indeed, a cross-cutting course in face-to-face mobilized a teaching for each training of a given level. In the pooled version put online, instead, the same course will no longer need to recruit several different teachers to provide it, but just few tutors for tutoring sessions. From a material point of view, the migration of the courses in distance leads in practice to the release of classrooms or tutorials for the planning of non-transversal courses; slots that were reserved for cross-cutting teachings will also be released. All this shows the positive impact of our model in optimizing the material and educational resources of a classical university, thus helping to solve the problem of insufficient resources.

Better harmonization of the courses according to the LMD: In classical universities, it is usual to observe that the same courses (or modules) of the same level are taught in different departments with distinct content. This leads to the problem of harmonization of course syllabi and content for the same level regardless the department; such a problem is mainly due to a lack of coordination between the departments regarding their size, the lack of time of the responsible teachers, and a better consultation and sharing during the setting up of the syllabuses.

If such a problem of harmonization is not so serious for domain-specific courses, it is more problematic for cross-cutting teachings because the objectives and competences targeted remain the same regardless of the specialty. In addition, this does not meet the concept of mobility advocated by the LMD system (License-MasterDoctorate), education system applied in Senegal. 
Our model of mutualisation is a perfect solution to this problem of transversal courses that are not uniforme. With pooling, we end up with a single content for each transversal module, thus promoting better mobility of students between departments. As an example, the ECT course, which was taught in L2, L3 and M1 to 9 separate cohorts, is now reduced to one and only one course per level; we then get 3 courses in total for all cohorts.

More flexibility in the course teaching process: Migrating transversal courses online and remotely with our model provides more flexibility in the way the course should be conducted. In the face-to-face setting, a given teaching must either be for one semester or spread over two semesters (i.e. courses must be spread over 12 or 24 weeks according to the LMD system). With the course conducted online and remotely, the teaching can be done any time during the academic year, and especially in sessions much shorter in time. This is made possible by the fact that the online course is accessible at any time regardless of our geographical position. On the other side, learners have full latitude to plan when to consult and learn the different chapters of a given course, thus breaking the strong constraint of always being present in class to follow the different parts of a course in classical teaching.

Better appropriation of ICTs in education: A good integration and appropriation of ICTs in higher education can be done at different levels, more or less related to used learning models and teaching techniques. The proposal of a model that translates cross-cutting courses of classical universities in distance learning is a concrete example. Our model thus allows a better ownership of the ICTs in the classical universities by favoring the following aspects:

- A better understanding and awareness of the importance of ICTs in learning and teaching;

- A training of teachers and learners on the use of the distance learning platform;

- A gradual familiarization of trainers and learners with digital tools as distance learning takes place; and

- A better support of the entire university community for the use of ICTs in education, increased by the positive impacts of our model.

Better monitoring and evaluation of learned courses: For monitoring purposes, the focus is made on organizing and observing tutoring sessions. The pedagogical approach of our model requires weekly scheduling of a 2-hour tutoring session for each group. Tutoring sessions are done technically using virtual classes. The objective sought here is the interactivity between the actors of the system which is an essential point of our approach. Tutoring is mandatory for the actors. The time of connections and the exchange of information during the tutoring hours are evaluated at each session by the system. This allows us, for example, to publish weekly statistics on connection hours for a learner and a teacher. Table 2 and Figure 7 show student statistics about the connection rates from seven training opportunities that have followed the seven-week tutoring sessions. 


\subsection{Financial impact}

In order to demonstrate the positive impact of our model in optimizing resources of a classical university, we have also realized a financial study on the budgetary impact of transversal teachings in ECT over a period of 3 years; these ECT courses have been then migrated and taught online using our model. This financial study concerns only the nine ECT components that are currently being conducted by IFoAD.

Table 2. Percentage of attendees of tutoring session per week

\begin{tabular}{|l|c|c|c|c|c|c|c|}
\hline & WEEK 1 & WEEK 2 & WEEK 3 & WEEK 4 & WEEK 5 & WEEK 6 & WEEK 7 \\
\hline L2 AMRT & $63,27 \%$ & $0,00 \%$ & $55,10 \%$ & $67,35 \%$ & $28,57 \%$ & $91,84 \%$ & $55,10 \%$ \\
\hline L2 WEB & $0,00 \%$ & $22,86 \%$ & $14,29 \%$ & $45,71 \%$ & $74,29 \%$ & grève & no session \\
\hline $\begin{array}{l}\text { L3 ECON- } \\
\text { OMIE }\end{array}$ & no session & $8,06 \%$ & $3,23 \%$ & $54,84 \%$ & $27,42 \%$ & $56,45 \%$ & no session \\
\hline L3 CA & no session & $0,00 \%$ & $60,00 \%$ & $20,00 \%$ & $30,00 \%$ & $90,00 \%$ & $90,00 \%$ \\
\hline L3 SID & no session & $5,56 \%$ & $58,33 \%$ & $30,56 \%$ & $50,00 \%$ & Strike & $58,33 \%$ \\
\hline L3 CYBER & no session & $11,43 \%$ & $11,43 \%$ & $40,00 \%$ & $62,86 \%$ & Strike & $74,29 \%$ \\
\hline $\begin{array}{l}\text { L3 } \\
\text { FONCIER }\end{array}$ & no session & $18,18 \%$ & $36,36 \%$ & $24,24 \%$ & $36,36 \%$ & Strike & $57,58 \%$ \\
\hline
\end{tabular}

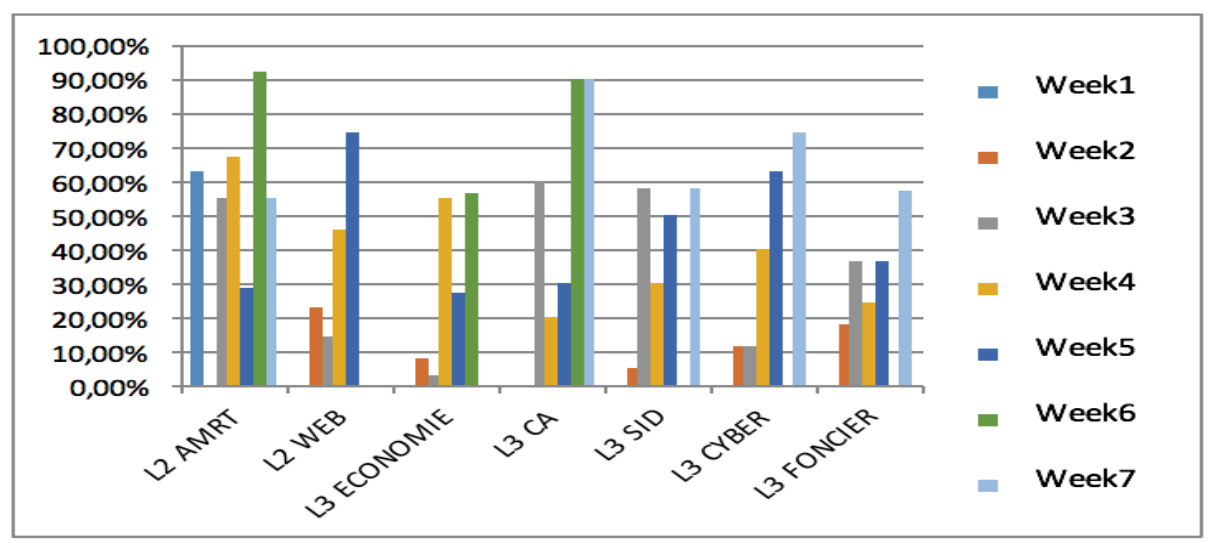

Fig. 4. Comparison of weekly connection rates for all specialities

Evaluation metrics: Our study of the financial impact of the implementation of our model was based on the training models of the departments of Alioune Diop University of Bambey and uses the following formulas (Equations 1 and 2). Those two formulas enable to make a comparison between the cost of a face-to-face transversal course and the cost at a distance education over a term, i.e. 12 weeks:

face_to_face_teaching_cost $=\left(\left(\mathrm{h} \_\right.\right.$rate_tuto_grps_Nbr $\left.\times 11.44 \mathrm{EUR}\right) \times($ rest price $\mathrm{x} 12)+($ avg_housing_price $\times 12)+($ transport_price $\times 12)$

Where rest_price, avg_housing_price and transport_price are equals to 3.81 EUR, 15.25 EUR and 3.81 EUR respectively. 
Distance_learning_cost $=($ uploading_cost $+($ hourly_rate $\times 2 \times 8$ weeks $))$

Where uploading_cost and hourly_rate are respectively worth 457.5 EUR et 8.39 EUR.

All the amount given above are standard ones which are applied at Alioune Diop University of Bambey when evaluating the cost of an external teacher who is recruited to give a face-to-face or online teaching. In a face-to-face scenario, an external teacher has a hourly payment rate and is taken in charge for the housing, transport and the food. In addition, the number of groups of students he has in his charge has to be taken into account for the total amount to be paid. In contrast, only the production of the online content and the number of teaching hours are paid for an online teaching scenario.

Results of the financial study: The different graphs in Figure 8 show a significant amortization of the cost of the ECT components from the first year and a gain of 8620 EUR over the 3 years, in the scenario where it is shared and dispensed entirely online and remotely.

The results of the evaluation of the impacts of our model in a classical university in Senegal showed that the transition from traditional to distance education produces results that strongly contribute to the optimization of the university's resources.

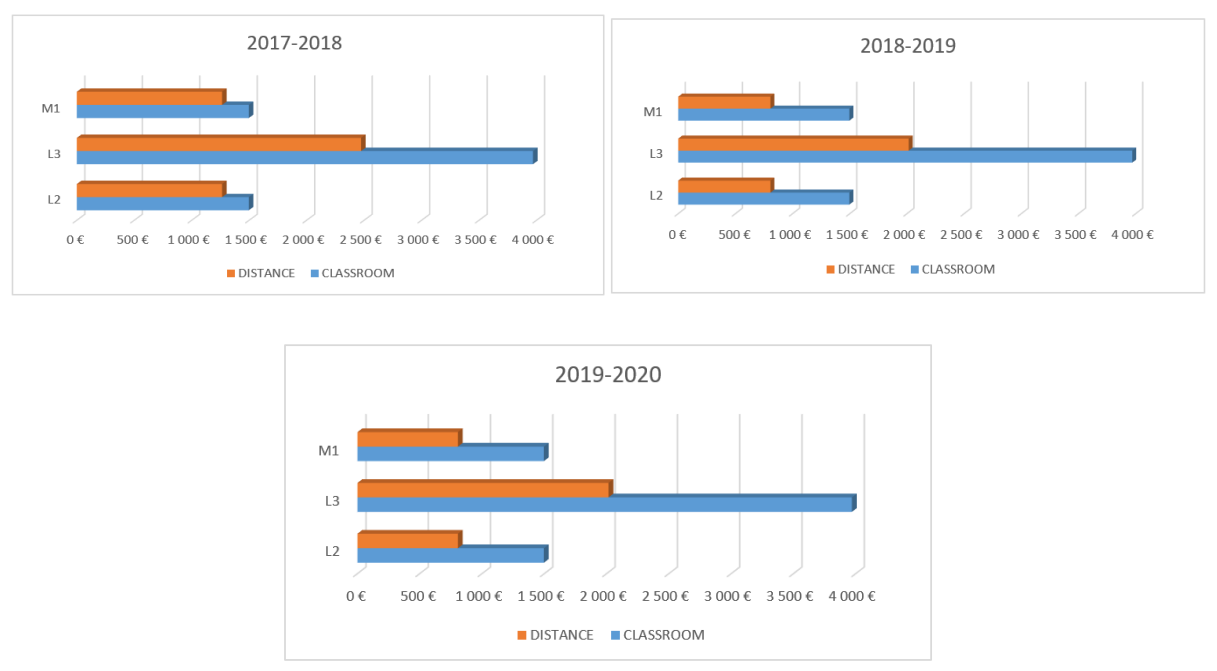

Fig. 5. Financial impact of the shift from face-to-face to distance education for the crosscutting component in "Expression and communication techniques".

\section{Conclusion}

In this paper, we have proposed a new model of migration of the cross-cutting courses of a traditional university in distance learning and have demonstrated its positive impacts in optimizing resources. The proposed model has been designed using a participatory and inclusive approach towards the university's leaders and departments 
of the different entities of the university in charge of classical pedagogy. Our migration approach is based on first identifying and pooling cross-cutting courses and then putting online the results: pooling requires to first identify certain basic courses of the departments taught in the human sciences (languages), economics and legal and political sciences, and then to mutualise them by level and specialty in order to produce the best courses in these disciplines. To evaluate the efficiency, i.e. positive impacts, of our model in a practical setting we implemented it at Alioune Diop University of Bambey in Senegal. The results of such an evaluation done during an entire school year have proved a real contribution at the pedagogical and financial point of views in the management of the university. Recall that this evaluation shows that our model allows to reduce the cost of a student with respect to the face-to-face model. The same model can be applied to any conventional university, at the national and international level, wishing to optimize its resources and give itself the means to strengthen its role and its place in the democratization of access to higher education. The next step for improving our model is to enhance our technical support strategies and the interactions between the students and their tutors, i.e. tutoring sessions.

\section{Acknowledgement}

We are grateful to the "Fonds d'Impulsion à la Recherche (FIR)" of Alioune Diop University of Bambey (UADB). We would like also to thank the Rector, the Faculties and departments of UADB for their help in the migration of cross-cutting courses.

\section{$7 \quad$ References}

[1] Mélanie Jacquemin \& Hamidou Dia. Les enfants hors ou en marge du système scolaire classique au Sénégal : Etude « ORLECOL »: synthèse analytique. IRD: fdi: 010069024, Dakar, Unicef, 2016.

[2] Conseil présidentiel sur l'enseignement supérieur et la recherche, 2013, [Online] Available: http://www.cres-sn.org/sites/default/files/cnaes decisions19aout-l.pdf.

[3] Amadou Dahirou Gueye, Marie Héléne Mballo, Omar Kassé, Bounama Gueye, Mouhamadou Lamine BA, Model of Integration of Distance Education in a Traditional University: Migration of Cross-cutting Courses to Distance Learning. In proceedings of the 21th International Conference on Interactive Collaborative Learning ICL 2018, Kos Island, Greece, pp. 1-12, 2019. https://doi.org/10.1007/978-3-030-11935-5 2

[4] M. Mastafi, (2015). Intégrer les TIC dans l'enseignement: Quelles compétences pour les enseignants?. Formation et Profession, vol. 23, $\mathrm{n}^{\circ}$ 12, 2015.

[5] A. Balanskat, R. Blamire et S. Kefala. The ICT Impact Report: A review of studies of ICT impact on schools in Europe. 2006.

[6] S. Machin, S. McNally et O. Silva. New Technology in Schools: Is There a Payoff?. 2006.

[7] T. Karsenti et F. Larose. Les TIC au coeur des pédagogies universitaires. Québec: Presses de l'Université du Québec.

[8] Dessalegn Mequanint et Dagmawi Lemma, (2014). L'intégration des TIC en pédagogie dans les pays en voie de développement. Revue internationale d'éducation de Sèvres, 67, pp. 75-84, 2014. https://doi.org/10.4000/ries.4117 
Paper-Impacts of the Migration of Cross-Cutting Courses of a Traditional University in Distance ..

[9] Pelgrum et Law. Les TIC et l'éducation dans le monde. Paris : UNESCO, Institut international de planification de l'éducation.

[10] Erkan Taskin. Distance education: A flexible teaching and learning delivery method. 2009 IEEE, Application of Information and Communication Technologies, Baku, Azerbaijan, 2009, 10.1109/ICAICT.2009.5372601

[11] M. Jimenez, S. Bartolomei-Suarez, Y. Ochoa and W. Santiago. A synchronous distance education hybrid model of college-level credits for high-school students. 2016 IEEE Frontiers in Education Conference, Eire, pp. 1-5, 2016. 10.1109/FIE.2016.7757723

[12] Université Virtuelle du Sénégal, 2015, [Online] Available: http://www.uvs.sn/.

[13] CVU, «UNIVERSITE VIRTUELLE CANADIENNE» 2009. [Online]. Available: http://www.cvu-uvc.ca/englishFR.html.

[14] TELUQ, [Online] Available: https://www.teluq.ca/

[15] WGU. Western Governors University, 2003. [Online]. Available: http://www.wgu.edu/.

[16] OPEN, «The open University», 2013. [Online]. Available: http://www.open.ac.uk/. .

[17] ULB. Université Libre de Bruxelles, 2013. [Online]. Available: http://www.ulb.ac.be/.

[18] T.CURSUS. Formation et culture numérique, 2009. [Online]. Available: http://cursus.edu/article/1752/une-universite-virtuelle-pour-rejoindre-population/

[19] Hernandez, Ronald M.. Impact of ICT on Education: challenges and Perspectives, journal of Educational Psychology, pp. 337-347, 2017.

[20] Linda Shear, Larry Gallagher and Deepa Patel. Innovative Teaching and Learning Research: 2011 Findings and Implications. SRI International, Nov. 2011, Available: https://www.sri.com/work/publications/innovative-teaching-and-learning-research-2011findings-and-implications.

[21] ITU, ICT Development Index, 2017, [Online] Available: http://www.itu.int/net4/ITUD/idi/2017/

[22] snRER, «Réseau pour l’Enseignement Supérieur et la Recherche du Sénégal», [Online] Available: http://snrer.edu.sn/index.php?option=com_content\&view=article\&id=50\&Itemid=115

[23] SONATEL, «Société National de Télécommunication» [Online] Available: http://sonatel.sn/

[24] ADIE, «Agence de l'Informatique de l'État» [Online] Available: https://www.adie.sn/

[25] MESRI, «Ministère de l'Enseignement supérieur, de la Recherche et de l'Innovation» [Online] Available: http://www.mesr.gouv.sn/

[26] PAES, «Projet d'Appui à l'Enseignement Supérieur» [Online] Available: https://www.afdb.org/fileadmin/uploads/afdb/Documents/Project-andOperations/Multinational - Support for Higher Education in WAEMU Countries Appraisal_Report.pdf

[27] PADTICE, «Projet d'Appui au Développement des Technologies de l'Information et de la Communication pour l'éducation» [Online] Available: http://www.unesco.org/new/fr/dakar/about-this-office/singleview/news/padtice a project to enhance african students daily life/

[28] AUF, «Agence universitaire de la Francophonie» [Online] Available: https://www.auf.org/

[29] Pape Mamadou Djidiack Faye, Amadou Dahirou Gueye and Claude Lishou. Proposal of a Virtual Classroom Solution with WebRTC Integrated on a Distance Learning Platform. In Proceedings of the $19^{\text {th }}$ ICL, Springer International Publishing, Vol. 544, $n^{\circ} 1,2017$.

[30] Gueye A.D., Faye P.M.D., Lishou C. Optimization of Practical Work for Programming Courses in the Context of Distance Education. Online Engineering \& Internet of Things, Lecture Notes in Networks and Systems, Springer Cham, vol. 22., 2018, https://doi.org/10.1007/978-3-319-64352-6 72 
[31] ZHU, Yaqiong. A Data Driven Educational Decision Support System. International Journal of Emerging Technologies in Learning, Vol. 13, n¹1, pp. 4-16, 2018, [Online] Available: http://online-journals.org/index.php/i-jet/article/view/9582.

[32] Monika Hattinger, Kristina Eriksson. Co-construction of Knowledge in Work-Integrated E-learning Courses in Joint Industry-University Collaboration. International Journal of Advanced Corporate Learning, Vol. 11, $\mathrm{n}^{\circ} 1$, pp. 10-16, 2018 [Online] Available: http://online-journals.org/index.php/i-jac/article/view/9152

[33] Annika Jokiaho, Birgit May, Marcus Specht, Slavi Stoyanov. Barriers to using E- Learning in an Advanced Way. Courses in Joint Industry-University Collaboration. International Journal of Advanced Corporate Learning, Vol. 11, $\mathrm{n}^{\circ}$ 1, pp. 17-22, 2018 [Online] Available: http://online-journals.org/index.php/i-jac/article/view/9235.

[34] Mutualisation online platform of the Online and Open Training Institute of Alioune Diop University of Bambey, Senegal. https://ifoad.uadb.sn/mutualisation/.

\section{Authors}

Mouhamadou Lamine Ba is an assistant professor in Computer Science and the head of the Research and Training Division of the Online and Open Learning Institute of Alioune Diop University of Bambey. He holds a PhD in Computer Science and Networks from Télécom ParisTech of Paris in France.

E-mail: mouhamadoulamine.ba@uadb.edu.sn

Bounama Gueye is an information systems and techno-pedagogical engineer at the Online and Open Learning Institute of Alioune Diop University of Bambey in Senegal. He holds a Master in Information Systems from Alioune Diop University of Bambey. E-mail: bounama . gueye@uadb.edu.sn

Amadou Dahirou Gueye is an assistant professor in Computer Science and the head of the Online and Open Learning Institute of Alioune Diop University of Bambey. He holds a PhD in Computer Science from the "École Supérieure Polytechnique" of Dakar in Senegal. E-mail: dahirou . gueye@uadb.edu.sn

Omar Kassé is the Web designer, graphist and the online content designer of the Online and Open Learning Institute of Alioune Diop University of Bambey. He has a strong experience regarding the Senegalese Education system with more than sixteen working years. E-mail: omar . kasse@ uadb.edu.sn

Marie Héléne W Mballo is the head of the Digital Educational project at the "Agence Universitaire de la Francophonie" of Dakar in Senegal. Previously, she has worked as a techno-pedagogical engineer at the Online and Open Training Institute of Alioune Diop University of Bambey in Senegal. E-mail: marie.bassene@auf.org

This article is a revised version of a paper presented at the International Conference on Interactive Collaborative Learning (ICL2018), held September 2018, in Kos, Greece. Article submitted 2018-11-30. Resubmitted 2019-01-30. Final acceptance 2019-01-30. Final version published as submitted by the authors. 